\title{
ALOIMUNIZAÇÃO ERITROCITÁRIA EM PACIENTES COM ANEMIA FALCIFORME ATENDIDOS NO HEMOCENTRO DE CARUARU, PERNAMBUCO, BRASIL
}

\author{
Willians Emanuel da Silva MELO ${ }^{1 *}$, Arthur Felipe Cordeiro FRAGA ${ }^{2}$, Maria do Carmo Morais Rodrigues \\ TORRES ${ }^{3}$, Edna Suely Feitosa PIRES $^{3}$ \& Fabrício Andrade Martins ESTEVES ${ }^{2,4}$
}

\begin{abstract}
1 Faculdade Uninassau, Departamento de Saúde. Caruaru, Pernambuco, Brasil.
2 Centro Universitário Tabosa de Almeida - ASCES UNITA. Caruaru, Pernambuco, Brasil.

3 Fundação de Hematologia e Hemoterapia de Pernambuco - HEMOPE. Caruaru, Pernambuco, Brasil.

4 Instituto de Estudos Avançados ASCES-UNITA. Caruaru, Pernambuco, Brasil.

*Autor para correspondência: williansmelo1@gmail.com
\end{abstract}

DOI: http://dx.doi.org/10.18571/acbm.160

\section{RESUMO}

Objetivos: A aloimunização eritrocitária é um problema grave em pacientes que recebem transfusões, principalmente no tratamento das hemoglobinopatias, como a anemia falciforme. Os objetivos desse trabalho são estabelecer a frequência da aloimunização eritrocitária em pacientes com anemia falciforme e apontar os fatores envolvidos na aloimunização. Métodos: Estudo descritivo transversal retrospectivo de prevalência, sendo levantadas informações sobre aloimunização e fatores associados, em pacientes com anemia falciforme atendidos pelo Hemocentro de Caruaru, entre janeiro de 1987 a dezembro de 2012. As informações foram obtidas a partir da consulta a dados no sistema de prontuários médicos do Hemocentro, tabuladas em planilhas do programa Excel 2007 (Microsoft Office®) e analisadas estatisticamente através do software R, utilizando o Teste Exato de Fisher e OddsRatio. Resultados: A produção de anticorpos irregulares foi identificada em 11 pacientes, representando uma taxa de aloimunização de $34 \%$. Os anticorpos encontrados foram: 05 anti-C (25\%), 05 anti-E (25\%), 03 anti-K (15\%), 01 anti-D (5\%), 01 anti-C $^{\mathrm{w}}(5 \%), 01$ anti-Fy ${ }^{\mathrm{a}}(5 \%), 01$ anti-Jk $^{\mathrm{a}}(5 \%), 01$ anti-S (5\%), 01 anti-Le ${ }^{\mathrm{a}}(5 \%)$ e 01 anti-Le ${ }^{\mathrm{b}}(5 \%)$. Observou-se que indivíduos com idade acima de 30 anos e pacientes que receberam acima de 10 concentrados de hemácias tiveram maior risco em desenvolver aloanticorpos. Conclusão: Transfusões de hemácias continuam sendo essenciais para o tratamento de complicações da anemia falciforme. A realização da fenotipagem eritrocitária poderá contribuir para reduzir a alosensibilização e consequentemente o número de reações transfusionais hemolíticas, aumentando a segurança transfusional e influenciando na qualidade de vida destes pacientes.

Palavras chave: Anemia falciforme; Transfusão Sanguínea; Anticorpos.

\begin{abstract}
Objectives: To determine the frequency of erythrocyte alloimmunization in patients with sickle cell anemia and estabilish the factors involved on alloimmunization. Methods: A descriptive cross-sectional retrospective prevalence, which will be raised about alloimmunization and associated factors in patients with sickle cell anemia treated by Caruaru Blood Center, from January 1987 to December 2012. The information was obtained from the data query system of medical records of the Blood Center, tabulated through Excel 2007 spreadsheet program (Microsoft Office ( ${ }^{\circledR}$ ) and statistically analyzed using the software R, using the Fisher's exact test and Odds Ratio. Results: The production of irregular antibodies in 11 patients were identified, representing a rate of $34 \%$ alloimmunization. The antibodies were:05anti-C (25\%), 05 anti-E (25\%), 03 anti-K (15\%), 01 anti-D (5\%), 01 anti-Cw(5\%), 01 anti-Fy ${ }^{\mathrm{a}}(5 \%), 01$ anti-Jk ${ }^{\mathrm{a}}(5 \%), 01$
\end{abstract}




\section{Biomedica Brasiliensia}

ISSN: 2236-0867

anti-S (5\%), 01 anti-Le ${ }^{\mathrm{a}}(5 \%)$ and 01 anti-Le ${ }^{\mathrm{b}}(5 \%)$. It was observed that individuals over the age of 30 years have a significant relative risk of 7.2 times more likely to be alloimmunized.There was a relationship of increased risk of alloimmunization in patients who received greater than 10 units of packed red blood cells. Conclusion: Transfusion of red blood cells remain essential for the treatment of some complications of sickle cell anemia, but the use of phenotyping help reduce alloimmunization and consequently the number of hemolytic transfusion reactions, increasing transfusion safety and positively influencing the quality of life of these patients.

Keywords: Sickle Cell Anemia; Blood Transfusion; Antibodies.

\section{Introdução}

A anemia falciforme (AF) é uma hemoglobinopatia de caráter hereditário, causada por uma mutação de ponto no gene da beta globina, gerando a hemoglobina S. Esta possui modificações físicas e químicas que conferem ao eritrócito uma maior rigidez e menor poder de deformabilidade na microcirculação e, quando em ambientes pobres em oxigênio, polimeriza-se, formando hemácias em foice. Os pacientes com essa patologia podem apresentar uma anemia hemolítica severa e contínua, em decorrência dadestruição dos eritrócitos pelo baço, sendo observado no seu hemograma um baixo nível de hemoglobina (MALOWANY, 2012; YAWN, 2014; YAZDANBAKHSH, 2012).

Indivíduos afetados por essa desordem hematológica geneticamente determinada apresentam episódios de crises álgicas, característicos da doença, desencadeados por fenômenos vasoclusivos, potencializados por ambientes submetidos a baixas tensões de oxigênio, promovendo a polimerização da hemoglobina $S$ e com consequente surgimento de poiquilocitose típica e surgimento de depranócitos. Eritrócitos assim deformados perdem potássio e água para o meio extracelular, levando a uma desidratação dos mesmos. A crise vasoclusiva geralmente é desencadeada por infecções agudas, em especial viroses e processos inflamatórios. A variação na sintomatologia da AF desencadeia nos pacientes desde a necessidade de transfusões de emergência, devido à anemia severa, ou nenhuma transfusão (MALOWANY, 2012; YAWN, 2014; YAZDANBAKHSH, 2012).

As transfusões de concentrados de hemácias $(\mathrm{CH})$ são importantes para os pacientes que possuem AF. Porém estas expõem os indivíduos ao risco de receberem hemácias com incompatibilidade de antígenos (ABO, Rh, Kell, Duffy, Kidd, MNs, Lewis). Esses antígenos, ao serem reconhecidos pelo sistema imune do indivíduo, podem desenvolver uma resposta que acarretará a formação de anticorpos irregulares, tornando-o aloimune, predispondo-o a reações transfusionais hemolíticas, caso ele entre em contato com estes mesmos antígenos, seja em futuras transfusões ou, no caso das mulheres, em gestações posteriores (CHOU, 2013; SMART, 2008; CHOU, 2012).

A aloimunização causada pela incompatibilidade entre antígenos do doador e do receptor do hemocomponente, desencadeia uma resposta imune de graus variados proporcionais à imunogenicidade e dose do (s) antígeno (s) incompatível (eis) podendo ocasionar o óbito. O desenvolvimento de anticorpos irregulares em pacientes politransfundidos é muito comum. Atualmente uma alternativa disponível para a prevenção da aloimunização é a realização da fenotipagem eritrocitária dos pacientes e das bolsas de sangue, a qual consiste em identificar quais antígenos estão presentes na superfície da hemácia, uma vez que indivíduos que não possuem determinado antígeno podem produzir anticorpos frente a sua exposição. Desta forma a realização da fenotipagem eritrocitária pode diminuir sensivelmente o número de reações transfusionais hemolíticas, aumentando a segurança e eficácia transfusional nesse grupo de indivíduos (CHOU, 2012; STACK, 2016). 
Traçar o perfil epidemiológico e a frequiência da produção dos aloanticorpos em pacientes com AF pode fornecer subsídios para respaldar a transfusão de hemocomponentes seguros para cada paciente, reduzindo riscos de aloimunização e consequentemente a ocorrência de reações transfusionais hemolíticas.

Os objetivos deste estudo são estabelecer a frequência de aloimunização eritrocitária e apontar os fatores envolvidos na aloimunização, através do perfil epidemiológico e imunohematológico de pacientes portadores de anemia falciforme atendidos pelo Hemocentro de Caruaru-PE, através da consulta aos prontuários médicos dos mesmos.

\section{Materiais e Métodos}

Estudo de abordagem descritiva, transversal retrospectiva de prevalência, com base nos dados secundários de prontuários. Foram levantadas as informações sobre a aloimunização e perfil epidemiológico dos pacientes com anemia falciforme atendidos pelo Hemope - Caruaru, no período de janeiro de 1987 a dezembro de 2012. Caruaru localiza-se na região agreste de Pernambuco, distante 136 quilômetros da capital do estado, Recife. Possui 351.686 habitantes, é sede da IV Região de Saúde de Pernambuco, a qual atende 32 municípios do agreste pernambucano. O Hemocentro de Caruaru realiza tanto as doações de sangue total quanto atende indivíduos com hemoglobinopatias, a exemplo da anemia falciforme e talassemias, sendo este último serviço oferecido pelos profissionais de maneira altruísta. A partir das consultas de rotina aos pacientes com AF são realizados a pesquisa de anticorpos irregulares e mais recentemente a fenotipagem eritrocitária.

Foram incluídos no estudo os prontuários dos pacientes com AF nos quais tenha sido realizada a pesquisa de anticorpos irregulares e excluídos os que não apresentaram tal informação. Também foram levantadas as informações sobre classificação ABO e Rh, idade, sexo, período de acompanhamento do paciente e quantidade de unidades de bolsas transfundidas. A tabulação dos dados foi realizada através de planilhas do programa Excel 2007 (Microsoft Office ${ }^{\circledR}$ ) e, a partir do qual foram confeccionadas tabelas e gráficos. A análise estatística dos dados foi feita por meio do software R, utilizando o Teste Exato de Fisher e Odds Ratio (OR), adotando-se como índice de significância o valor de 5\%. A escolha pelos métodos estatísticos descritos se deu em virtude do poder de comparação entre grupos (aloimunes e não-aloimunes) para se estabelecer a chance de desenvolver anticorpos frente às situações apresentadas. Foram comparados os grupos de pacientes aloimunes e não aloimunes frente a faixa etária, gênero e quantidade de transfusões recebidas.

A presente pesquisa foi submetida e aprovada pelo Comitê de Ética em Pesquisa do Centro Universitário Tabosa de Almeida - ASCES UNITA, sob o número 198.851.

\section{Resultados}

Foram incluídos neste estudo 32 pacientes nos quais a pesquisa de anticorpos antieritrocitários irregulares foi realizada. Destes, $17(53,12 \%)$ eram do sexo masculino e 15 $(46,87 \%)$ do sexo feminino. As idades dos indivíduos avaliados variaram entre 9 a 59 anos, sendo que a maioria (38\%) dos pacientes tinham idade entre 10 e 19 anos.

No período de 1987 a dezembro de 2012 foram transfundidas um total de 443 unidades de $\mathrm{CH}$ nos pacientes com AF. As transfusões variaram entre 0 e 84 unidades por paciente.

Dos 32 pacientes, $3(9,37 \%)$ não receberam nenhuma transfusão, $13(40,62 \%)$ receberam até 5 unidades, $5(15,62 \%)$ receberam até 10 unidades, $2(6,25 \%)$ receberam até 15 transfusões e $9(28,12 \%)$ receberam mais que 15 unidades.

A produção de anticorpos irregulares foi identificada em 11 pacientes, representando uma taxa de aloimunização de 34\%. Os anticorpos encontrados foram: 05 anti-C (25\%), 05 anti-E (25\%), 03 anti-K (15\%), 01 anti-D (5\%), 01 anti-C ${ }^{\mathrm{w}}(5 \%), 01$ anti-Fy $^{\mathrm{a}}(5 \%), 01$ anti-Jk ${ }^{\mathrm{a}}(5 \%)$, 


\section{Biomedica Brasiliensia}

ISSN: 2236-0867

01anti-S (5\%), 01 anti-Le ${ }^{\mathrm{a}}(5 \%)$ e 01 anti-Le ${ }^{\mathrm{b}}(5 \%)$, sendo todos os anticorpos diagnosticados da classe IgG. (Tabela 1).

Tabela 1: Distribuição de Anticorpos irregulares identificados no Hemocentro de Caruaru - PE, no período de 1987 a 2012.

\begin{tabular}{|c|c|c|}
\hline $\begin{array}{l}\text { Especificidade } \\
\text { do Anticorpo }\end{array}$ & $\mathbf{n}^{\mathbf{0}}$ & $\%$ \\
\hline \multicolumn{3}{|l|}{ Sistema Rh } \\
\hline anti-C & 5 & 25 \\
\hline anti-E & 5 & 25 \\
\hline anti-D & 1 & 5 \\
\hline anti-C $\mathrm{C}^{\mathrm{w}}$ & 1 & 5 \\
\hline \multicolumn{3}{|l|}{ Sistema Kell } \\
\hline anti-K & 3 & 15 \\
\hline \multicolumn{3}{|l|}{ Sistema Duffy } \\
\hline anti-Fy & 1 & 5 \\
\hline \multicolumn{3}{|l|}{ Sistema Kidd } \\
\hline anti-Jk ${ }^{\mathrm{a}}$ & 1 & 5 \\
\hline \multicolumn{3}{|l|}{ Sistema MNS } \\
\hline & 1 & 5 \\
\hline \multicolumn{3}{|l|}{ Sistema Lewis } \\
\hline anti-Le ${ }^{a}$ & 1 & 5 \\
\hline anti-Le ${ }^{b}$ & 1 & 5 \\
\hline TOTAL & 20 & 100 \\
\hline
\end{tabular}

Dentre os pacientes aloimunizados, 6 (55\%) eram do sexo masculino e $5(45 \%)$ eram do sexo feminino. O resultado do teste de qui-quadrado não apresentou risco de aloimunização associado ao gênero (valor de $p>0.05$ ) (Tabela 2).

Os indivíduos participantes deste estudo foram categorizados em duas faixas etárias, conforme demonstrado na Tabela 2. Assim sendo, foi realizada uma análise de frequência entre estas duas categorias também por meio da aplicação do teste de qui-quadrado. Observou-se que indivíduos com idade acima de 30 anos, portadores de AF possuem risco relativo significativo de 7,2 vezes mais chances de serem aloimunizados (valor de $p<0.05$ ). 
Tabela 2: Análise de frequência entre portadores de anemia falciformeimunizados e não-imunizados, quanto à faixa etária e gênero no Hemocentro de Caruaru - PE, no período de 1987 a 2012.

\begin{tabular}{|c|c|c|c|c|c|c|c|}
\hline & & \multicolumn{2}{|c|}{ Não-aloimunes } & \multicolumn{2}{|c|}{ Aloimunes } & \multirow[b]{2}{*}{ O.R. (IC 95\%) } & \multirow[b]{2}{*}{ Valor de p } \\
\hline & & $\mathbf{n}^{\mathbf{o}}$ & $(\%)$ & $n^{0}$ & $(\%)$ & & \\
\hline \multirow{2}{*}{$\begin{array}{l}\text { Faixa } \\
\text { etária }\end{array}$} & 0 a 29 anos & 18 & 78.36 & 5 & 21,74 & & \\
\hline & $\geq 30$ anos & 3 & 33.33 & 6 & 66.66 & 7.2(1.17-2.40) & 0.024 \\
\hline \multirow[t]{2}{*}{ Gênero } & Masculino & 11 & 64.70 & 6 & 35.30 & & \\
\hline & Feminino & 10 & 66.66 & 5 & 33.33 & $0.94(0.23-3.73)$ & 0.601 \\
\hline
\end{tabular}

Quanto ao número de transfusões recebidas, observou-se que houve uma maior proporção de aloimunizados entre os que receberam mais de dez transfusões. Calculando o OR, constatou-se relação de maior risco de aloimunização com número de transfusões acima de 10 unidades de $\mathrm{CH}$, o que representou uma chance de 7,4 vezes a mais em desenvolver algum aloanticorpo, pois os aloimunizados receberam, em média, 26 transfusões de $\mathrm{CH} /$ paciente, enquanto que nos não aloimunizados a média foi de 7,47 transfusões/paciente (Tabela 3.).

Tabela 3: Análise de risco de aloimunização quanto à quantidade de concentrados de hemácias transfundidos em portadores de anemia falciforme no Hemocentro de Caruaru-PE, no período de 1987 a 2012.

\begin{tabular}{ccccccc}
\hline $\begin{array}{c}\text { Quantidade de CH } \\
\text { transfundidos }\end{array}$ & \multicolumn{2}{c}{ Não aloimunes } & \multicolumn{2}{c}{ Aloimunes } & O.R. (IC 95\%) & Valor de p \\
\cline { 2 - 5 } & $\mathbf{n}^{\mathbf{0}}$ & $(\boldsymbol{\%})$ & $\mathbf{n}^{\mathbf{0}}$ & $\mathbf{( \% )}$ & & \\
\hline 1 A 10 & 17 & 80,95 & 4 & 19,05 & & \\
& & & & & & \\
> 10 & 4 & 36,36 & 7 & 63,63 & $7,43(1,440 ; 38,411)$ & 0,017 \\
\hline
\end{tabular}

\section{Discussão}

Um dos maiores riscos transfusionais é a aloimunização do receptor contra os antígenos presentes no sangue transfundido. Observou-se no presente estudo que, dos 32 pacientes atendidos pelo Hemocentro de Caruaru, nos quais foi possível investigar a produção de aloanticorpos antieritrocitários, 34\% foram alosensibilizados, sendo fatores de risco significativamente estatísticos possuir mais de 30 anos e ter recebido mais de 10 unidades de concentrados de hemácias.

A frequência de aloimunização mostrou-se compatível com os dados da literatura. Algumas pesquisas demostram taxas que variam de 12 até 50\% (FABRON, 2001; AMEEN, 2009; BORDIN, 2007).

No estudo de Ameen et al (2009) foram avaliados 233 pacientes com doença falciforme atendidos no Kuwait Central Blood Bank, estes foram divididos em dois grupos: Grupo 1 ( $\mathrm{n}=$ 110) receberam transfusão de hemácias através do padrão $\mathrm{ABO}$ e Rh-D compatível, e o Grupo 2 $(\mathrm{n}=123)$ receberam hemácias compatíveis por $\mathrm{ABO}, \mathrm{Rh}$, e $\mathrm{K} .65 \%$ dos pacientes do grupo 1 desenvolveram anticorpos contra $23,6 \%$ do grupo 2. Os anticorpos mais frequentes estavam associados aos sistemas $\mathrm{Rh}(\mathrm{C}, \mathrm{c}, \mathrm{E}, \mathrm{e}, \mathrm{D})$ e Kell (K1). A média geral de aloimunização entre os dois grupos foi de $43,3 \%$. Este estudo evidencia que os pacientes que recebem $\mathrm{CH}$ compatíveis paraoutros antígenos além do $\mathrm{ABO}$ e $\mathrm{Rh}$, desenvolvem menos anticorpos. 
A maior ocorrência de aloanticorpos foi contra os antígenos dos sistemas Rh e Kell, fato que é de acordo com outros autores, pois ambos os sistemas contêm antígenos altamente imunogênicos (FABRON, 2001; AMEEN, 2009; PINTO, 2011; MILLER, 2012; SCHONEWILLE, 2006; SCHONEWILLE， 2009; TORMEY， 2008; SANTOS， 2007; NATUKUNDA, 2010).

Os anticorpos anti-C e anti-E, ambos direcionados contra o sistema $\mathrm{Rh}$ corresponderam a $50 \%$ dos anticorpos identificados (25\% cada). A alta frequência de tais anticorpos é confirmada pela literatura (FABRON, 2001; AMEEN, 2009; PINTO, 2011; MILLER, 2012; SCHONEWILLE， 2006; SCHONEWILLE， 2009; TORMEY， 2008; SANTOS， 2007; NATUKUNDA, 2010). No estudo de Miller et al (2010) o anti-C e o anti-E corresponderam a $35,18 \%$ dos anticorpos identificados nos pacientes com doença falciforme.

$\mathrm{O}$ anti-K, direcionado contra o sistema Kell $\left(3^{\circ}\right.$ grupo de antígenos eritrocitários mais imunogênico) correspondeu a 15\% dos ACS encontrados, a ocorrência de tal anticorpo concorda com Tormey et al., onde a taxa do aloanticorpo anti-K foi de $21,9 \%$, bem como em outras pesquisas (FABRON, 2001; AMEEN, 2009; PINTO, 2011; MILLER, 2012; SCHONEWILLE, 2006; SCHONEWILLE, 2009; TORMEY, 2008; HELMAN, 2011).

Quanto ao gênero, os percentuais de aloimunização não demonstraram diferença de frequência com significado estatístico. O presente resultado ratifica, portanto com o relatado por Fabron et al (2001) e Helman et al (2011).

Quanto à faixa etária, houve correlação significativa entre idade e risco de aloimunização, fato que está de acordo com o estudo realizado por Pinto et al (2011), onde os pacientes aloimunizados tenderam a apresentar idademaior (24,6 anos) que os não-aloimunizados (11,5 anos). Na população de pacientes com AF aqui avaliada, indivíduos com faixa etária maior que 30 anos obtiveram uma chance 7,2 vezes maior de desenvolver anticorpos irregulares que os pacientes com faixa etária menor que 30 anos, fato este que deve estar associado à condição de cronicidade que a doença decursa.

Não se observou qualquer correlação entre aloimunização e os diferentes tipos sanguíneos do sistema ABO, à semelhança de outros autores (SANTOS, 2007; ALVES, 2012).

Alguns estudos, mostram que quanto maior o número de transfusões, maior o risco de aloimunização (PINTO, 2011; SANTOS, 2007; NATUKUNDA, 2010; HELMAN, 2011; ALVES, 2012). Natukunda et al (2010) avaliaram 214 pacientes transfundidos por diversas doenças, destes, 13 apresentaram anticorpos antieritrocitários, sendo que 11 receberam mais que 10 transfusões, evidenciando ser fator significante receber mais que $10 \mathrm{CH}$ para o risco de se tornar aloimunizado, fato também observado nestes achados. A média de transfusões nos pacientes que produziram anticorpos foi de $26 \mathrm{CH}$, maior que a média nos não-imunizados, que ficou em 7,47 CH.

Transfusões de hemácias continuam sendo essenciais para o tratamento dealgumas complicações da AF, porém devido aos riscos associados a elas, se tem buscado na prática transfusional diminuir as chances de um indivíduo se tornar aloimunizado, sendo as alternativas disponíveis a fenotipagem e genotipagem eritrocitária. Estas técnicas reduzem os índices ou mesmo a existência da aloimunização. A fenotipagem é preconizada para os antígenos C, c, E, e, e K, mais imunogênicos, permitindo assim reduzir significativamente a produção de aloanticorpos antieritrocitários. Já a genotipagem é apontada como técnica para elucidação de casos onde a fenotipagem é ineficaz para conclusão dos resultados (COSTA, 2013; CHOU, 2013; WILKINSON, 2011; SLOAN, 2016).

Os anticorpos anti-C, anti-E e anti-K foram os mais diagnosticados no presente estudo. Estes aloanticorpos possuem significância clínica e estão em plena concordância com o relatado pela literatura. Na população de pacientes com AF aqui avaliada, foi observada correlação entre número de transfusões e idade com a aloimunização.

A implementação da fenotipagem eritrocitária não só para pacientes com AF, mas para toda a população que faça uso de transfusões em regime crônico contribuirá para reduzir a 
alosensibilização, e consequentemente, o número de reações transfusionais hemolíticas, melhorando a qualidade da hemoterapia e da segurança transfusional no Brasil, bem como influenciando positivamente na qualidade de vida destes pacientes.

\section{Referências}

ALVES V.M.; MARTINS P.R.J.; SOARES S et al. Alloimmunization screening after transfusion of red blood cells in a prospective study. Rev Bras Hematol Hemoter 2012; 34(3):206-211. http://dx.doi.org/10.5581/1516-8484.20120051.

AMEEN R.; SHEMMARI S.A.L.; AL-BASHIR A. Red blood cell alloimmunization among sickle cell Kuwaiti Arab patients who received red blood cell transfusion. Transfusion 2009; 49(8):1649-1654. http://dx.doi.org/10.1111/j.1537-2995.2009.02185.x.

BORDIN J.O. Aloimunização após transfusão de concentrado de hemácias em pacientes atendidos em um serviço de emergência. Rev Bras Hematol Hemoter 2007; 29(4):339-340. http://dx.doi.org/10.1590/s1516-84842007000400001.

CHOU S.T.; JACKSON T.; VEGE S et al. High prevalence of red blood cell alloimmunization in sickle cell disease despite transfusion from Rh-matched minority donors. Blood. 2013a; 122 (6): 1062-1071. http://dx.doi.org/10.1182/blood-2013-03-490623.

CHOU S.T.; LIEM R.I.; THOMPSON A.A. Challenges of alloimmunization in patients with haemoglobinopathies.Br J Haematol 2012; 159(4):394-404. http://dx.doi.org/10.1111/bjh.12061.

CHOU S.T. Transfusion therapy for sickle cell disease: a balancing. act. Hematol 2013b; 2013(1):439-446. http://dx.doi.org/10.1182/asheducation-2013.1.439.

COSTA D.C.; PELLEGRINO JR. J.; GUELSIN G.A.S et al. Molecular matching of red blood cells is superior to serological matching in sickle cell disease patients. Rev Bras Hematol Hemoter 2013; 35(1):35-38. http://dx.doi.org/10.5581/1516-8484.20130012.

FABRON A. Estudo da significância clínica de aloanticorpos eritrocitários em pacientes com anemia falciforme. Rev Bras Hematol Hemoter 2001; 23(2):121-122. http://dx.doi.org/10.1590/s1516-84842001000200011.

HELMAN R.; CANÇADO R.D.; OLIVATTO C. Incidence of alloimunization in sickle cell disease: experience of a center in São Paulo. Einstein 2011; 9(2):160-164. http://dx.doi.org/10.1590/s1679-45082011ao2003.

MALOWANY J.I.; BUTANY J. Pathology of sickle cell disease. Seminars In Diagnostic Pathology 2012; 29 (1): 49-55. http://dx.doi.org/10.1053/j.semdp.2011.07.005.

MILLER S.T.; KIM H.Y.; WEINER D.L et al. Red blood cell alloimmunization in sickle cell disease: prevalence in 2010. Transfusion 2012; 53(4):704-709. http://dx.doi.org/10.1111/j.15372995.2012.03796.x.

NATUKUNDA B.; SCHONEWILLE H.; VAN DE WATERING L. et al. Prevalence and specificities of red blood cell alloantibodies in transfused Ugandans with different diseases. Vox Sanguinis 2010; 98(2):167-171. http://dx.doi.org/10.1111/j.1423-0410.2009.01241.x. 
PINTO P.C.A.; BRAGA J.A.P.; SANTOS A.M.N. Fatores de risco para aloimunização em pacientes com anemia falciforme. Rev Assoc Méd Bras 2011; 57(6):668-673. http://dx.doi.org/10.1590/s0104-42302011000600014.

SANTOS F.W.R.; MAGALHÃES S.M.M.; MOTA R.M.S et al. Post-transfusion red cell alloimmunisation in patients with acute disorders and medical emergencies. Rev Bras Hematol Hemoter 2007; 29(4):369-372. http://dx.doi.org/10.1590/s1516-84842007000400009.

SCHONEWILLE H.; VAN DE WATERING L.M.G.; LOOMANS D.S.E et al. Red blood cell alloantibodies after transfusion: factors influencing incidence and specificity. Transfusion 2006; 46(2):250-256. http://dx.doi.org/10.1111/j.1537-2995.2006.00708.x.

SCHONEWILLE H.; VRIES R.R.; BRAND A. Alloimmune response after additional red blood cell antigen challenge in immunized hematooncology patients. Transfusion 2009; 49(3):453-457. http://dx.doi.org/10.1111/j.1537-2995.2008.01980.x.

SLOAN S.R. The importance of antibody screens after transfusions. Transfusion 2016; 56(11):2653-2654. http://dx.doi.org/10.1111/trf.13818.

SMART E.; ARMSTRONG B. Blood group systems. ISBT Science Series 2008; 3 (2): 68-92. http://dx.doi.org/10.1111/j.1751-2824.2008.00188.x.

STACK G.; TORMEY C.A. Detection rate of blood group alloimmunization based on real-world testing practices and kinetics of antibody induction and evanescence. Transfusion 2016; 56 (11): 2662-2667. http://dx.doi.org/10.1111/trf.13704.

TORMEY C.A.; FISK JOHN.; STACK G. Red blood cell alloantibody frequency, specificity, and properties in a population of male military veterans. Transfusion 2008; 48 (10): 2069-2076. http://dx.doi.org/10.1111/j.1537-2995.2008.01815.x.

WILKINSON K.; HARRIS S.; GAUR P et al. Molecular blood typing augments serologic testing and allows for enhanced matching of red blood cells for transfusion in patients with sickle cell disease. Transfusion 2011; 52(2):381-388. http://dx.doi.org/10.1111/j.1537-2995.2011.03288.x.

YAWN B.P.; BUCHANAN G.R.; AFENYI-ANNAN A.N et al. Management of Sickle Cell Disease. Jama 2014; 312 (1): 1033-1048. http://dx.doi.org/10.1001/jama.2014.10517.

YAZDANBAKHSH K.; WARE R.E.; NOIZAT-PIRENNE F. Red blood cell alloimmunization in sickle cell disease: pathophysiology, risk factors, and transfusion management. Blood 2012; 120 (3):528-537. http://dx.doi.org/10.1182/blood-2011-11-327361. 